\title{
Índices sociais de valor: mass media, linguagem e envelhecimento*
}

Denise Regina Stacheski ${ }^{1}$

Gisele Aparecida Athayde Massi²

STACHESKI, D.R.; MASSI, G.A.A. Social value indices: mass media, language and aging. Interface - Comunic., Saude, Educ., v.15, n.37, p.425-36, abr./jun. 2011.

This paper aimed to analyze the media discourse in relation to the process of human aging, through news reports published in the newspaper Gazeta do Povo (city of Curitiba, state of Paraná southern Brazil) and collected in 2008. The reports were organized and analyzed from the following aging stereotypes found in social practice: aging and degeneration of biological functions, aging and the absence of a social role for the elderly, and aging and the active elderly, responsible for their old age. The study is of interest both to health professionals - such as speech therapists and psychologists, who work with a conception that considers language as constitutive of subjects -, and to social communication professionals, who work with the media and interfere in social representations, in the social mental imagery.

Keywords: Aging. Mass Media. Language.
O objetivo deste trabalho foi analisar os discursos midiáticos frente ao processo do envelhecimento humano, por meio de notícias publicadas no jornal Gazeta do Povo (Curitiba, Paraná) coletadas no ano de 2008. As notícias foram organizadas e analisadas com base nos seguintes estereótipos da velhice encontrados na prática social: o envelhecimento e a degeneração das funções biológicas; o envelhecimento e a ausência do papel social do idoso, e o envelhecimento e o idoso ativo, responsável frente à velhice. O estudo é de interesse tanto dos profissionais da saúde - como fonoaudiólogos e psicólogos, que trabalham em torno de uma concepção que toma a linguagem como trabalho constitutivo dos sujeitos -, quanto dos profissionais de comunicação social que trabalham com a mídia e que realizam grande interferência nas representações sociais, no imaginário social.

Palavras-chave: Envelhecimento. Mass media. Linguagem.

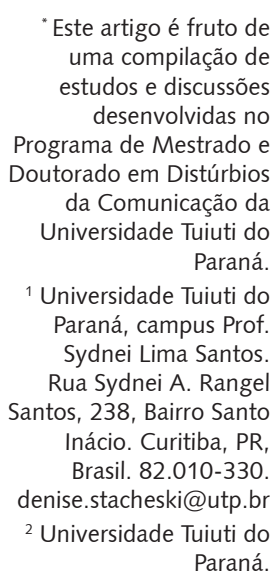

Paraná. 


\section{Índices sociais de valor: mass media, linguagem e envelhecimento}

Este artigo tem como objetivo analisar os discursos midiáticos frente o processo do envelhecimento humano, com base em valores constituídos socialmente a respeito do envelhecer e da população idosa. O tema é de interesse interdisciplinar aos profissionais da saúde, da comunicação social, da linguagem, entre outros.

Os discursos midiáticos e a perspectiva da constituição dos sujeitos pela linguagem anunciam a necessidade de um trabalho complexo, e em conjunto, para que novas significações sobre o envelhecimento sejam construídas na sociedade em que vivemos.

O texto pautou-se nos estudos de autores das seguintes áreas: da linguagem (Faraco, 2003; Mussalim, 2001; Bakhtin, 1997), da antropologia (Debert, 1999), da saúde (Papaléo Neto, 2007) e da comunicação (Stam, 2010; Wolf, 1987) - que, de maneira interdisciplinar, se entrelaçam, quando o tema é envelhecimento social.

\section{Perspectiva sócio-histórica da linguagem e os índices sociais de valor do envelhecimento}

Na perspectiva sócio-histórica da linguagem, toda ação humana precede uma interação social. Parte do pressuposto de que a linguagem tem papel constitutivo do sujeito por meio das relações dialógicas estabelecidas com o outro. Desde pequena, a criança insere-se no mundo da linguagem, percebendo e interagindo com o outro, construindo significados e valores sobre o mundo que a cerca.

Diferentemente das teorias behavioristas ou inatistas, a perspectiva sócio-histórica argumenta que as concepções de mundo partem da prática discursiva entre as ideologias sociais existentes. Bakhtin (1997, p.35) afirma que "a consciência individual é um fato sócio-ideológico" e que "todo signo é ideológico por natureza". Assim, a consciência dos indivíduos adquire forma e existência a partir de signos e significações criados por um grupo organizado em função da história de suas práticas sociais. Essa interação de significados é, justamente, o que constitui a verdadeira linguagem para Bakhtin (1997).

$\mathrm{O}$ ato da fala e os discursos produzidos socialmente estão carregados de conteúdos ou de sentidos ideológicos e vivenciais. Uma linguagem viva, um processo incessante que é construído no cotidiano da vida social. Segundo Bakhtin (1997, p.42), "cada época e cada grupo social têm seus repertórios de formas de discurso na comunicação sócio-ideológica". Por meio desses repertórios e de suas significações, os sujeitos se constituem.

A criação ideológica, para a perspectiva sócio-histórica da linguagem, não pode ser reduzida em sua superfície empírica, nem limitada a uma consciência individual e, sim, pelo viés social e histórico. Segundo Faraco (2003, p.64), "para haver relações dialógicas, é preciso que qualquer material lingüístico tenha entrado na esfera do discurso, tenha sido transformado num enunciado, tenha fixado a posição de um sujeito social [...]".

Os índices sociais de valor, conforme Faraco (2003), condizem aos valores axiológicos/culturais de cada grupo social. Uma configuração hierarquizada de valores humanos, a valoração dos fatos e das coisas do mundo a partir dos contextos individuais e sociais. Segundo Bakhtin (1997), assim como as interações sociais, o interindividualismo também está presente na construção axiológica dos sujeitos. Por este motivo, existem múltiplas e heterogêneas formas de compreensão das enunciações realizadas. Essas diferenças nos permitem entender que o sujeito é responsivo, que ele participa ativamente do processo de interação social, na medida em que atribui sentido aos enunciados produzidos nas diferentes situações discursivas.

Diferentes visões acerca do idoso são encontradas na coletividade, que, de maneira dialógica, acabam se misturando no cotidiano e formando estereótipos da velhice na prática social. Dentre as vozes sociais sobre o envelhecimento, levantadas por meio das notícias publicadas no Jornal Gazeta do Povo (vide metodologia), estão: o envelhecimento e a degeneração das funções biológicas, o envelhecimento e a ausência do papel social do idoso, e o envelhecimento e a responsabilidade do idoso frente à velhice. A seguir, está apresentada a fundamentação sobre cada vertente. 


\section{O envelhecimento e a degeneração das funções biológicas}

Papaleo Netto (2007) toma a definição biológica do envelhecimento como um processo, e a velhice como uma fase da vida. As manifestações somáticas da velhice, conforme o autor, caracterizadas por redução da capacidade funcional, calvície e redução da capacidade de trabalho e da resistência, entre outras, associam-se a: perda dos papéis sociais, solidão e perdas psicológicas, motoras e afetivas.

O conceito biológico do envelhecimento, acima citado, pode ser traduzido como o fim do caminho biológico. A velhice, nesta visão, se constitui de tristezas, de fraquezas e de debilitações físicas, emocionais e psicológicas.

Segundo Meassi (2008), a velhice ainda é comumente associada a um completo declínio, tanto das capacidades físicas, como da intelectual e da saúde (física e mental). Como os idosos necessitam de cuidados médicos especiais, conforme essa visão, áreas voltadas às prevenções de doenças são assuntos predominantes nos meios de comunicação, nas notícias levantadas, quando se fala em velhice.

\section{O envelhecimento e a ausência do papel social do idoso}

Outra visão de envelhecimento percebida é aquela que propõe uma falta de papel social do idoso. O fato de ações e projetos brasileiros para a população idosa visarem, muitas vezes, apenas, o entretenimento, mostra, segundo Goldfarb (1998), que a sociedade mascara a visão que aponta para a inutilidade dos velhos com atividades exclusivamente lúdicas, desprezando a sua experiência e seus conhecimentos acumulados - fortalecendo uma noção de que o velho não pode contribuir para a vida social. Cabe salientar que as atividades de entretenimento são relevantes, mas os programas destinados aos idosos não devem se limitar a essa vertente exclusiva.

Com o advento da industrialização e da urbanização, que privilegia a força produtiva, os velhos foram isolados da engrenagem social, caracterizando-se pela ausência de papel social (Debert, 1999). Idosos não ativos socialmente, em uma sociedade capitalista, na qual os modos econômicos de produção exigem força física para a produção industrial em massa, formatando novo estereótipo a respeito da velhice, o idoso passivo, excluído socialmente.

Nessa visão, problemas econômicos, culturais e psicológicos são vivenciados por essa parcela da população que não encontra "voz" em uma coletividade despreparada para lidar e conceber a velhice. Papaléo Netto (2007, p.11) afirma que o resultado dessa situação "é a marginalização do velho e a perda de sua condição social, às quais se associam aos poucos rendimentos recebidos, frutos de aposentadorias irrisórias".

Quando o sujeito começa a vivenciar a velhice, às vezes, alguns referenciais podem se perder, algumas referências que tiveram presentes em toda a sua vida e que demonstravam quem ele era e seu posicionamento social. Por exemplo: se esse sujeito tinha voz ativa nas decisões de sua família, hoje, velho, ele não é mais consultado, ele não faz mais parte fundamental do diálogo familiar. Esse momento pode ser bastante conturbado, pois o idoso se concebe como um desconhecido para si mesmo, já não localiza seu papel dentro dos ambientes sociais. Essa perda de referência, de autonomia, de posição ativa, se agrava quando a família e a sociedade não atribuem um papel social ativo ao idoso, considerando-o inútil, um peso social.

\section{O envelhecimento e a responsabilidade do idoso frente à velhice}

A terceira visão do envelhecimento, trabalhada neste artigo, surge a partir da década de 1990, com o discurso em relação aos idosos que vêm se modificando na sociedade. Com o aumento mundial da população idosa, novos discursos sociais estão em construção. Nessa perspectiva, o idoso não é mais visto como um excluído, inclusive, em discursos políticos. Debert (1999) questiona as razões para essas mudanças discursivas e, até mesmo, questiona sobre a responsabilidade individual que a sociedade está impondo a cada sujeito frente a sua possibilidade de envelhecer de forma saudável. Segundo a autora: 
A publicidade, os manuais de auto-ajuda e as receitas de especialistas estão empenhados em mostrar que as imperfeições do corpo não são naturais, nem imutáveis e que, com esforço e com trabalho corporal disciplinado, pode-se conquistar a aparência desejada; as rugas e a flacidez se transformam em indícios de lassitude moral e devem ser tratadas com a ajuda dos cosméticos, das ginásticas, das vitaminas, da indústria do lazer. (Debert, 1999, p. 20)

Assim, os sujeitos devem controlar seu corpo e se responsabilizar por suas decadências físicas, retirando dos âmbitos sociais o dever de lidar com a população idosa. Debert (1999) afirma que os sujeitos, a partir dessa visão, não são apenas monitorados para exercerem uma vigilância constante do corpo, mas são responsabilizados pela sua própria saúde, por meio das concepções de doenças autoinfligidas, resultado de abusos corporais, como a bebida, o fumo, a falta de exercícios físicos. A autora também argumenta que, nesta vertente, a boa aparência é igual ao bem-estar. Os sujeitos que conservam seus corpos por meio de dietas, exercícios e outros cuidados viverão mais. Essa visão exige dos sujeitos uma autovigilância da saúde corporal e da boa aparência.

Rodrigo e Soares (2006) afirmam que a sociedade brasileira privilegia os sujeitos mais jovens em detrimento dos mais velhos, refletindo o sistema de produção vigente. Essa classificação cronológica pela idade dos sujeitos gera uma série de problemas em torno do idoso, pois limita o pleno exercício da cidadania das pessoas acima de sessenta anos de idade.

As três visões a respeito do envelhecimento discutidas acima estão separadas metodologicamente neste artigo, porém vale ressaltar que, na prática social, elas se entrelaçam. As vertentes interagem e se sobressaem de acordo com cada sujeito social.

\section{Os mass media e o envelhecimento}

As palavras são as matérias-primas de trabalho dos profissionais dos meios de comunicação. E os discursos midiáticos são uma via de interação social, promovendo, também, significações que constituem as diversas visões de mundo. Assim, por meio de interações verbais e não verbais, a construção discursiva dos produtos midiáticos interfere na sociedade e nos sujeitos que a compõem.

Machado (2005) afirma que os usos da linguagem e todas as suas esferas ocorrem de forma dependente. Isto é, os discursos dos meios de comunicação de massa se tornam uma referência direta aos enunciados concretos que se manifestam nos discursos sociais. Uma existência cultural, que, segundo a autora, "reverbera em tudo, uma vez que nela, as formas culturais vivem sob as fronteiras", uma cadeia complexamente organizada. "A linguagem como manifestação viva das relações culturais" (Machado, 2005, p.163).

As palavras e os discursos dos mass media penetram em todas as relações sociais, "nas relações de colaboração, nas de base ideológica, nos encontros fortuitos da vida cotidiana, nas relações de caráter político, etc. As palavras são tecidas a partir de uma multidão de fios ideológicos e servem de trama a todas as relações sociais em todos os domínios" (Bakhtin, 1997, p.4).

Para Wolf (1987), os meios de comunicação desempenham uma função importante na sociedade, na medida em que agem como elementos ativos da mesma estrutura coletiva/social, das definições e modos de vida de um grupo determinado.

Os mass media são responsáveis por produzirem e divulgarem os fatos cotidianos de uma sociedade. Quando descrevem e organizam os fatos da realidade exterior, os meios de comunicação de massa apresentam ao público uma lista sobre o que consideram ser necessário ter uma opinião e discutir, silenciando demais aspectos da sociedade. Por meio da agenda (conteúdos abordados) realizada pelos meios de comunicação de massa, os sujeitos sociais constroem, em grande parte, seus índices valorativos sobre os assuntos presentes na mídia. Não só percebem o outro, o externo, como, também, percebem as suas próprias características subjetivas e se estereotipam frente às diversas visões presentes na coletividade. 
É importante salientar que o sujeito não é passivo nesse jogo das palavras ideológicas. A internalização da cultura não é simplesmente imitativa do entorno, existe todo um ativo e sistemático (contínuo) processo de re-significação. É possível que novos significados sejam construídos por meio da linguagem e dos contextos sociais. Os significados se constituem de experiências anteriores já fortalecidas, discursos que ecoam para a significação momentânea. Isto é, os meios de comunicação de massa formam um sistema de cultura, constituindo-se como um conjunto de símbolos, valores, mitos e imagens que interagem na vida prática e no imaginário coletivo (Wolf, 1987). No entanto, a mídia não é o único sistema cultural das sociedades contemporâneas, pois elas são realizações policulturais. Stam (2010, p.333) argumenta que existem, sim, padrões de supremacia, e tendências ideológicas, "mas a dominação nunca é completa", porque, para o autor, os meios de comunicação de massa não se constituem apenas dos seus próprios donos e gestores, mas, também, são constituídos pelos seus participantes ativos e criativos, como os funcionários e a audiência - que podem "resistir, pressionar e decodificar".

Os sujeitos refletem os fatos exteriores produzidos e divulgados pela mídia e refratam na medida das significações de outros campos sociais, como uma cadeia de enunciações, uma cadeia constitutiva de valores. Na interação entre o sujeito e a informação midiática, acontece, também, a constituição de significados a partir de uma eterna negociação de valores, de significados, de manifestações simbólicas que formam a cultura de uma sociedade.

Os mass media, na maioria de seus enunciados, apresentam os idosos e o processo de envelhecimento com base em fatores negativos à sociedade, como o fim biológico e a ausência de papel social dos velhos. Apesar de apresentarem alguns discursos sobre a "pró-atividade" dos idosos, sobressai o índice de valor social voltado para a dependência econômica e a percepção do envelhecimento como problema familiar e social - a partir de seu papel não produtivo na sociedade.

A partir do ano de 2006, a questão do envelhecimento e de temas relacionados com os idosos se fortaleceu na agenda dos mass media brasileiros. Basta verificar o aumento de produção jornalística a respeito do tema, em todo o país: editorias específicas, cadernos jornalísticos exclusivos, programas de televisão dirigidos. Porém, para Debert (1999), a imagem da terceira idade produzida pela mídia não tem viabilizado possibilidades para a sociedade lidar com problemas físicos e emocionais dos mais velhos. São mensagens que afloram e abordam mercadologicamente um público-alvo consumidor. Debert (1999) alerta, portanto, para o fato de que o sucesso do empreendimento de novas iniciativas voltadas para a terceira idade é proporcional à precariedade dos mecanismos de que dispomos para lidarmos com os problemas da velhice avançada. Por isso, a necessidade de crescente reflexão social sobre esse segmento populacional.

\section{Procedimentos metodológicos}

O objetivo desse trabalho é discorrer sobre os valores sociais construídos a respeito do envelhecimento nos mass media, conforme discussão teórica anteriormente apresentada.

Para isso, foi realizada uma análise discursiva e dialógica, pautada segundo a perspectiva de Bakhtin, de notícias publicadas no jornal Gazeta do Povo (Curitiba/ Paraná), no ano de 2008. A escolha do meio de comunicação se justifica por ser o maior jornal impresso do Paraná, em relação à sua tiragem e à sua distribuição. O jornal foi fundado em 2 de fevereiro de 1919. Com circulação estadual diária, o jornal pertence ao grupo RPC - Rede Paranaense de Comunicação, formada, ainda, por oito emissoras de TV filiadas à Rede Globo, pelas emissoras de rádio 98 FM e Mundo Livre FM, de Curitiba, pelo JL - Jornal de Londrina e pelo portal RPC.com.br. Uma empresa de comunicação com significativa expressão social no estado do Paraná e no Brasil.

Importante ressaltar que, como corpus de investigação acadêmica, as notícias de um jornal impresso são consideradas fontes públicas, de livre acesso para serem discutidas e analisadas, não necessitando de autorizações prévias das empresas jornalísticas. Em todas as notícias, são citados os jornalistas autores, a data de sua publicação, bem como a editoria onde foi publicada. 
A seguir, o detalhamento das etapas realizadas:

a) $1^{\text {a }}$ etapa: captação das notícias

O corpus foi retirado da versão digitalizada da Gazeta do Povo, disponibilizada no endereço eletrônico - www.gazetadopovo.com.br, contemplando matérias jornalísticas publicadas no ano de 2008. Para se obterem as notícias relacionadas à temática, foi utilizado o sistema de busca disponível no sítio do jornal, com as seguintes palavras: envelhecimento, idosos e terceira idade. Dessa busca, mais de 900 resultados gerais foram encontrados.

b) $2^{a}$ etapa: seleção da editoria vida e cidadania: saúde, educação e terceira idade.

A segunda etapa metodológica voltou-se a selecionar a editoria vida e cidadania como foco para a análise das notícias. Essa editoria foi escolhida por trabalhar com temas direcionados ao cotidiano do cidadão, abordando assuntos como: saúde, trabalho, educação, terceira idade, campanhas, entre outros. Para especificar o tema analisado, selecionamos as subeditorias de saúde, de educação e da terceira idade, por entender que o processo dialógico social entre essas áreas corresponde à construção dos índices sociais de valor, apresentados anteriormente. Segundo Queiroz e Netto (2007, p.815), "pode-se afirmar que sociabilidade e educação são dois dos maiores responsáveis pela promoção do envelhecimento saudável e, como conseqüência, para melhorar a qualidade de vida". A seleção das reportagens da editoria vida e cidadania contabilizou um número de sessenta notícias vinculadas às visões do envelhecimento anteriormente discutidas.

As sessenta notícias foram analisadas discursivamente sobre seu conteúdo, com base em uma perspectiva dialógica, que possibilita o estabelecimento de relações entre a linguagem e a sociedade que se constitui historicamente (Bakhtin, 1997). Para este artigo, foram sorteadas, aleatoriamente, dez notícias para a amostra de conteúdo e análise dialógica, fundamentada em Bakhtin.

c) $3^{a}$ etapa: representações sociais da velhice

A terceira etapa se caracterizou por organizar e analisar as dez notícias selecionadas a partir de três estereótipos da velhice encontrados na prática social: o envelhecimento e a degeneração das funções biológicas; o envelhecimento e a ausência do papel social do idoso, e o envelhecimento e o idoso ativo, responsável frente à velhice.

\section{Análise do corpus}

A seguir, estão apresentados, de forma sucinta, os conteúdos das dez notícias selecionadas aleatoriamente, bem como a análise realizada para este artigo.

1 - "Para manter a memória em dia" (editoria: vida e cidadania; subeditoria: saúde; publicada em: 14/07/2008; jornalista: Cecília Valenza).

Dado analisado: esta notícia traz o seguinte texto: "embora a perda da capacidade de memorização seja algo natural da idade, é preciso saber identificar o que está por trás dos esquecimentos e lembrar que a mente segue a lei do uso e desuso; ou seja, quanto mais estimulada, melhor será seu funcionamento".

Análise: encontramos neste dado, especialmente, a visão do envelhecimento e a degeneração das suas funções biológicas. As informações dessa notícia destacam a perda da memória em decorrência do envelhecimento, expõem o processo como algo natural, mas, que, se estimulada por meio de técnicas específicas, a capacidade de memorização pode melhorar. Percebe-se que a relação entre o envelhecimento e a perda das funções de memória é apresentada como inerente ao processo de envelhecimento, o fim do caminho biológico e de suas funções regulares.

A notícia apresenta e se entrelaça, também, em outra visão destacada neste artigo, que trata o envelhecimento e a responsabilidade do idoso frente à velhice. Expõe uma fórmula pronta para que os idosos se responsabilizem por manterem sua memória em dia. Como abordado anteriormente, os sujeitos, a partir dessa visão, devem controlar seu corpo e se responsabilizarem por suas alterações físicas. A notícia desvincula qualquer diagnóstico a partir da construção social e histórica do sujeito. 
Isto é, aborda as funções da memória como uma função estritamente física/cerebral, sem alavancar demais possibilidades sócio-históricas do sujeito idoso, suas experiências emocionais e as próprias concepções do idoso frente à velhice.

2 - "Idosos também sofrem de anorexia" (editoria: vida e cidadania; subeditoria: saúde; publicada em: 15/05/2008; jornalista: Aline Peres).

Dado analisado: a notícia alerta para o fato de que a anorexia, embora em número reduzido de casos, também afeta a terceira idade. Segundo o texto da notícia: "a doença fica ainda mais agressiva e de difícil tratamento por causa da fragilidade imposta pela idade". Depois, o texto enumera alguns sinais de alerta e de comportamentos para a identificação da doença.

Análise: o conteúdo da notícia anuncia a fragilidade dos velhos diante de doenças tão "jovens", como a anorexia. O texto expõe um idoso frágil e que apresenta processos mais lentos de cura. Demonstra, também, uma visão das perdas fisiológicas da velhice e percebe o idoso como um ser inativo frente às suas dificuldades emocionais e físicas. A velhice se constitui, para essa visão, de tristezas, de fraquezas e de debilitações físicas, emocionais e psicológicas. Engloba, dessa maneira, a visão do envelhecimento e a ausência do papel social do idoso. Em nenhum momento, a reportagem aborda questões sobre o ambiente social, cultural e histórico do sujeito.

3 - "Câncer deve atingir 234 mil mulheres em 2008" (editoria: vida e cidadania; subeditoria: saúde; publicada em: 08/03/2008; jornalista: Kamila Mendes Martins).

Dado analisado: a notícia retrata o aumento da expectativa de vida da população e, com ela, o aumento de casos de câncer no país. Salienta a importância da prevenção, e afirma: "se, por um lado, a longevidade é uma das principais razões para o aumento da doença, o diagnóstico tardio é o maior motivo para as mortes". O conteúdo faz uma relação entre o aumento de idosos e o aumento de câncer no Brasil, demonstra a fragilidade no envelhecimento e as debilidades fisiológicas advindas dele.

Análise: as visões de debilidade física e responsabilidade da prevenção pelo idoso são encontradas nesse dado. Meassi (2008) também acorda que a velhice ainda é comumente associada a um completo declínio, tanto das capacidades físicas, como da intelectual e da saúde (física e mental). Como os idosos necessitam de cuidados médicos especiais, dentro dessa visão, áreas voltadas para as prevenções de doenças são assuntos predominantes nos meios de comunicação, quando se fala em velhice. Ponte trabalha, igualmente, com a ideia de que os meios de comunicação realizam enormes apelos em relação à imagem do próprio corpo dentro das variadas redes de comunicação existentes em nossa sociedade. Segundo o autor, "por toda parte vemos e ouvimos sugestões para que façamos constantes esforços no sentido da manutenção de um corpo belo e jovem. Dietas para emagrecer; ginásticas ativas e passivas; para manter o corpo em forma; pílulas para combater o envelhecimento" (Ponte, 2007, p.275). Se tivermos que combater o envelhecimento é porque o mesmo, nesta concepção, está atrelado a uma situação negativa, algo semelhante a uma doença a ser curada.

4 - "Amigos a postos contra a solidão" (editoria: vida e cidadania; subeditoria: terceira idade; publicada em: 10/07/2008; jornalista: Anna Paula Franco).

Dado analisado: na notícia é destacada a convivência de idosos com animais de maneira positiva, servindo, até mesmo, de recomendação terapêutica, pelas vantagens como companheirismo, carinho e alegria. Segundo a jornalista, em seu texto: "e para os idosos, que passam mais tempo em casa e muitas vezes ficam sozinhos, essa relação assume uma importância ainda maior". O texto explora, também, a Atividade Assistida por Animais (AAA) como ajuda para o resgate da autoestima dos idosos.

Análise: o velho, na notícia, é apresentado como isolado socialmente, dotado de uma baixa autoestima, e que a alternativa, buscada por esses idosos, é a companhia de animais. Essa reportagem traz a visão do envelhecimento e a ausência do papel social do idoso, bem como, de forma entrelaçada, fortalece a ideia de fim do caminho biológico. Coloca o idoso como inativo social e 
passivo frente às dificuldades encontradas. Nessa visão, a sociedade não prevê um papel específico ou uma atividade para os velhos, abandonando-os a uma existência sem significado, caracterizandoos como uma minoria desprivilegiada, com baixa renda e baixo status. O idoso, neste julgamento de valor, constitui um problema social e aceita sua posição de excluído. Ressalta-se, assim, como descrito anteriormente, que o sujeito é responsivo frente a suas significações. Como afirma Goldfarb (1998, p.7), em seu trabalho sobre o Corpo, tempo e envelhecimento:

nosso ponto de partida será uma idéia predominantemente presente na nossa sociedade segundo a qual se atribui a sujeitos de diferentes idades cronológicas um estado de decrepitude e inutilidade, sem esquecer que as próprias vítimas, frequentemente, assumem este lugar e incentivam estas atitudes.

5 - "Fim da linha ou recomeço?" (editoria: vida e cidadania; subeditoria: terceira idade; publicada em: 03/07/2008; redação).

Dado analisado: a notícia traz a informação de que o Hospital San Julian, especializado em dependentes químicos, localizado em Piraquara, região metropolitana de Curitiba/PR, tem trezentos e cinquenta pacientes internados. Desses, 22 são idosos, segundo a enfermeira, Viviane Teixeira, citada na matéria, que afirma: "quadros depressivos também são comuns em pacientes idosos que apelam para a bebida". O texto expõe que há casos clássicos que evidenciam as dependências químicas nos idosos, como o abandono familiar, a exclusão social. Como o de um paciente, ex-garçom, que foi abandonado pela família. O conteúdo aborda estatisticamente idosos internados com problemas de álcool ou droga vinculados a uma posição social de abandono e de isolamento.

Análise: a notícia também se enquadra na visão do envelhecimento pautada na ausência do papel social, quando, ao trabalhar com a ideia do fim do caminho social, o conteúdo também se vincula à ideia do fim do caminho biológico. Quando o sujeito começa a vivenciar a velhice, às vezes, alguns referenciais podem se perder. Algumas referências que tiveram presentes em toda a sua vida, e que demonstravam quem ele era e seu posicionamento social, podem parecer sem sentido. Esse momento pode ser bastante conturbado, pois o idoso se concebe como um desconhecido para si mesmo, e já não localiza seu papel dentro dos ambientes sociais. Essa perda de referência, de autonomia, de posição ativa, se agrava quando a família e a sociedade não atribuem um papel social ativo ao idoso, considerando-o inútil, um peso social.

6 - "Atendimento a idosos começa em casa" (editoria: vida e cidadania; subeditoria: terceira idade; publicada em 14/08/2008; jornalista: Anna Paula Franco).

Dado analisado: a notícia destaca "o programa de atendimento de saúde básico, criado há 15 anos pelo governo federal, para pulverizar os serviços médicos primários a população". O programa tem o objetivo de mapear a situação de moradores de cada casa visitada pela equipe dos profissionais de saúde. O conteúdo salienta, também, "que a rotina de visitas e o monitoramento também ajudam na prevenção de agravamentos de doenças e a redução de complexidade dos males que atingem o idoso...". A notícia aborda novas estratégias de atuação de profissionais de saúde para conseguir atender as doenças e as necessidades dos idosos.

Análise: o texto aborda o idoso de forma fragilizada, demonstrando os esforços estruturais para atendê-lo. Tratar da velhice nas sociedades industrializadas é traçar um quadro dramático da perda do status social dos indivíduos, segundo Debert (1999). A industrialização destruiu a segurança econômica e as relações estreitas que vigoravam nas sociedades tradicionais entre as gerações de família. Assim, os idosos se transformam em um peso para a família e para o Estado. Nas sociedades modernas, o empobrecimento e os preconceitos são características marcantes, que levam ao abandono social e uma existência sem significado (Debert, 1999). Ser velho em uma sociedade liberal-capitalista é ser um velho dependente, um peso - ele está excluído da construção da história e da formação das próximas gerações, suas experiências de vida nada valem, pois o que oferta valor na sociedade atual é a sua posição dentro do mercado de trabalho. 
7 - "Semana de osteoporose tem exames gratuitos" (editoria: vida e cidadania; subeditoria: saúde; publicada em: 07/08/2008; redação).

Dado analisado: a notícia explica que a perda da massa óssea é provocada pela queda da taxa hormonal, sobretudo em mulheres acima de cinquenta anos, e informa sobre a Semana de Osteoporose e dados sobre a prevenção da doença. Segundo o texto: "Alimentação saudável e equilibrada, atividade física regular e exames preventivos de investigação de densidade óssea ajudam a controlar o problema". O conteúdo apresenta uma campanha de prevenção da doença destinada à terceira idade.

Análise: novamente, o discurso da fragilidade está presente. A notícia apresenta, também, fórmulas preestabelecidas que - se seguidas - poderão amenizar o processo da doença, responsabilizando os sujeitos pelo próprio envelhecimento saudável. Trabalha com a visão biológica, bem como com a visão do envelhecimento e a responsabilidade do idoso frente à velhice. Segundo Jardim (2007), os discursos presentes na nossa coletividade pautam-se nas perdas físicas, psíquicas e sociais dos idosos. As perdas físicas são representadas pela fraqueza, diminuição de força e da vitalidade orgânica. As perdas psíquicas representadas pelo declínio da memória, pela anulação da vida afetiva e pelo desinteresse em construir novas relações e adquirir novos conhecimentos. As perdas sociais estão vinculadas como um ser não produtivo, um ser dependente, à margem da construção da história em curso (Jardim, 2007). Uma visão do idoso que o toma como um peso social, reduzindo a velhice a uma situação desagradável.

8 - "Vovô foi ao baile... e se casou" (editoria: vida e cidadania; subeditoria: terceira idade; publicada em: 12/06/2008; jornalista: Anna Paula Franco).

Dado analisado: a notícia inicia com a estatística do IBGE afirmando que a taxa de casamento cresce mais entre a população idosa. E afirma: "Iongevidade, tempo de sobra e atividades sociais contribuem para essa tendência". Segundo a notícia, a longevidade e a mudança nos hábitos de vida dos mais velhos contribuem para a socialização dos idosos. Amplia a rede de relacionamentos, forma novos casais e coloca, como positiva, a existência de grupos de convivência e atividades sociais dirigidas ao público idoso e a responsabilidade do idoso para que participe desses grupos. Anuncia um idoso ativo, responsivo pelos seus atos. E fortalece a questão da interação social na velhice, a troca de experiências.

Análise: a notícia aborda as questões da responsabilidade do idoso frente às suas condições de velhice, bem como trabalha com a questão do tempo livre e da ausência do papel social do idoso. Com o desenvolvimento da ciência do envelhecimento, comprovou-se que não há necessidade de ligar o fato de envelhecer bem ou mal às superstições sobrenaturais, pois, mesmo não tendo uma única teoria a respeito do envelhecer, a ciência moderna trouxe muitos argumentos que fundamentam o processo da velhice.

9 - "Experiência de vida ajuda na hora de aceitar a morte" (editoria: vida e cidadania; subeditoria: terceira idade; publicada em: 29/05/2008; jornalista: Anna Paula Franco).

Dado analisado: a notícia retrata idosos que frequentam os Amigos Solitários no Luto, grupo de apoio em que eles: "compartilham histórias de vida, de saudade, de sentimentos que não foram expressos". O texto aborda, também, a questão de como os mais velhos, de forma homogênea, aceitam a morte mais tranquilamente que os mais jovens. O conteúdo traz a importância da interação verbal/social na velhice, fortalece a importância de suas experiências de vida aos participantes de um grupo de apoio, e demonstra uma maturidade em relação a assuntos delicados aos mais jovens.

Análise: a notícia traz a imagem de um idoso experiente, como se todos os idosos tivessem, de forma homogênea, tranquilidade frente à morte - com um papel ativo e responsivo para ajudar outros sujeitos na compreensão dos acontecimentos da vida. 
10 - "O prazer de cultivar amigos de longa data" (editoria: vida e cidadania; subeditoria: terceira idade; publicada em: 04/12/2008; jornalistas: Anna Paula Franco e Adriana Czelusniak).

Dado analisado: a notícia aborda reuniões periódicas de senhores e senhoras que apostam na importância da amizade, em todas as fases da vida. A notícia coloca: "os meninos da Caixa Econômica Federal jogam bola juntos há trinta anos". Enfatiza um ambiente descontraído para jogar conversa fora. Laços que unem os sujeitos, espaço para trocar experiências, dividir alegrias e frustrações.

Análise: o conteúdo demonstra aspectos positivos do envelhecimento por meio das reuniões de amigos antigos, fortalecendo a importância da interação verbal/social e a troca de experiências de vida. Traz uma ideia de descontração, de amizade, de companheirismo. O sentimento dos idosos frente à velhice é um reflexo subjetivo, uma consequência de significações das coisas do mundo, das ações e das atitudes firmadas e possibilitadas pelo sujeito, dentro de sua coletividade, desde o seu nascimento. As doenças crônicas podem aparecer no idoso, comprovando, sim, a baixa de suas funções fisiológicas - no entanto, se controladas, as doenças podem não causar nenhuma consequência negativa na vida dos idosos. Não enfatizar exclusivamente a saúde ou a beleza física também facilita o envelhecimento bem-sucedido, apostando em obter bons resultados dentro das capacidades do momento. Isto é, viver bem a velhice, encarar a velhice e vivê-la plenamente com seus aspectos positivos e negativos, ter a possibilidade de aceitá-la como um processo natural e adaptar as ações cotidianas.

Tendo em vista a análise das dez reportagens apresentadas, convém ressaltar a necessidade de o processo de envelhecimento não ser generalizado e homogeneizado. Para cada sujeito, dependendo de seus contextos socioculturais, a velhice pode corresponder a valores positivos e satisfatórios ou negativos e desconfortáveis.

\section{Considerações finais}

As visões discorridas e as análises realizadas das notícias publicadas pelo Jornal Gazeta do Povo refletem e refratam as visões sociais dos idosos. De maneira entrelaçada, as visões estão e se apresentam no discurso social. Se, de um lado, os próprios idosos se constituem a partir de uma concepção que os toma como problemas sociais e fomentam as enunciações de abandono, de fragilidade - de outro lado, os próprios idosos podem refratar essa visão exposta, se responsabilizando, de forma ativa, pela vivência de um envelhecimento saudável. Um sujeito social de ponta a ponta, mas individual de ponta a ponta (Bakhtin, 1997). Um idoso que se constitui pelas vozes sociais encontradas na coletividade e que pode refratá-las para a formação de novos significados.

Várias vozes sociais, como já observamos, concebem o envelhecimento como um fato negativo. $O$ idoso, por sua vez, pode ou não internalizar esses preconceitos. Se internalizarem essas concepções, segundo Grossi e Santos (2003), provavelmente se comportarão de acordo com o julgamento de valor exposto, mas se não as internalizarem - e desafiarem essas visões -, preservando sua identidade podem refratar os preconceitos construídos.

Grossi e Santos (2003, p.31) afirmam que o envelhecimento não se traduz apenas em perdas biológicas, mas em ganhos que advêm da "experiência acumulada, da capacidade de enxergar além, de escutar mais do que falar, de poder comunicar-se com sabedoria os ensinamentos às gerações futuras"; valorizar a velhice é valorizar a própria vida humana em sua plenitude. Nesta visão, o velho é concebido como um ser experiente e que pode se adaptar frente aos obstáculos.

A qualidade de vida na velhice é um fenômeno complexo e com múltiplas interfaces, tendo, como referências, critérios biológicos, sociais e psicológicos que, de forma conjunta com os relacionamentos atuais, passados e as prospecções futuras, constituem os sujeitos. Além desses aspectos existem os valores individuais e sociais dos idosos, que, subjetivamente, constroem as expectativas de como se deve viver a velhice, comparando as alterações no decorrer do tempo (Simson, Giglio, 2001). A concepção do que é ter qualidade de vida, nos idosos, por si só, já é uma questão subjetiva, que se insere dentro da construção cultural e social dos sujeitos. 
Bakhtin, nas notas de caderno de 1943, citado por Faraco (2005, p.43), reflete essa angústia: “o que ocorre, de fato, é que quando me olho no espelho, em meus olhos no espelho não vejo o mundo com meus próprios olhos e desde o meu interior; vejo a mim mesmo com os olhos do mundo - estou possuído pelo outro". O idoso pode perceber a si mesmo pelos olhos sociais que encontra, refletindo, somente, a visão das debilidades das funções físicas, ou pode superar a questão do declínio físico por meio de sua experiência de vida. São várias as vozes sociais e contraditórias que permeiam o envelhecimento; o idoso pode aceitá-las de forma passiva, se constituindo como um problema social, ou a partir de qualquer outro estereótipo formado, ou pode recusar essa posição posta socialmente e se constituir por outras visões adquiridas pela vida.

É necessário, sim, elevar hierarquicamente a valorização do idoso, pois, na autocontemplação, representamos um reflexo de nosso exterior, e não a nós mesmos. Segundo Bakhtin, nunca estamos sozinhos diante de um espelho. Um segundo elemento, o outro, o social, sempre participa no processo da autocontemplação, são os índices sociais de valor historicamente constituídos em sociedades, pela interação social, pela perspectiva da linguagem histórica que se encontra no dia a dia.

\section{Colaboradores}

As autoras trabalharam juntas em todas as etapas da elaboração do manuscrito.

\section{Referências}

BAKHTIN, M. Marxismo e filosofia da linguagem. São Paulo: Hucitec, 1997.

BRAIT, B. Bakthin: conceitos-chave. São Paulo: Contexto, 2005.

DEBERT, G.G. A reinvenção da velhice. São Paulo: Edusp, 1999. Disponível em: <http://books.google.com/books>. Acesso em: 15 set. 2009.

FARACO, C.A. Autor e autoria. In: BRAIT, B. (Org.). Bakhtin: conceitos-chave. São Paulo: Contexto, 2005.

2003.

. Linguagem e diálogo: as idéias lingüísticas do círculo de Bakhtin. Curitiba: Criar,

GOLDFARB, D.C. Corpo, tempo e envelhecimento. São Paulo: Casa do Psicólogo, 1998. Disponível em: <http://www.portaldoenvelhecimento.net/artigos/corpo.pdf>. Acesso em: 20 jan. 2010.

GROSSI, P.; SANTOS, A. Velho, eu? Pijama e chinelo só para dormir. In: DORNELLES, B.; COSTA, G.J.C. (Orgs.). Investindo no envelhecimento saudável. Porto Alegre: EDIPUCRS, 2003. p.27-35.

JARDIM, S.E.G. Aspectos socioeconômicos do envelhecimento. In: PAPALEO NETTO, M. (Org.). Tratado de Gerontologia. 2.ed. São Paulo: Atheneu, 2007. p.185-98.

MACHADO, A. A televisão levada a sério. São Paulo: Senac São Paulo, 2005.

MEASSI, C.G. A construção social do idoso a partir da representação midiática. 2008. Disponível em: <http://www.faac.unesp.br/pesquisa/idosomidia_antigo/docscarla. html>. Acesso em: 14 abr. 2011.

MUSSALIM, F. Análise do discurso. In: MUSSALIM, F.; BENTES, C. (Orgs.). Introdução à lingüistica: domínios e fronteiras. São Paulo: Cortez, 2001. p.101-42. 
PAPALEO NETTO, M. Tratado de gerontologia. São Paulo: Atheneu, 2007.

PONTE, J.R. Aspectos psicanalíticos do envelhecimento normal. In: (Org.). Tratado de Gerontologia. 2.ed. São Paulo: Atheneu, 2007. p.267-78.

QUEIROZ, Z.; PAPALEO NETTO, M. Envelhecimento bem-sucedido: aspectos biológicos, psicológicos e socioculturais - importância da sociabilidade e da educação. In: PAPALEO NETO, M. (Org.). Tratado de gerontologia. São Paulo: Atheneu, 2007. p.807-15.

RODRIGUES, L.S; SOARES, G.A. Velho, idoso e terceira idade na sociedade contemporânea. Revista Ágora, n.4, p.1-29, 2006. Disponível em: <http://www.ufes.br/ ppghis/agora >. Acesso em: 28 jan. 2010.

SIMSON, O.R.M.; GIGLIO, Z.G. A arte de recriar o passado: história oral e velhice bem sucedida. In: NERI, A.L. (Org.). Desenvolvimento e envelhecimento. Campinas: Papirus, 2001. p.141-60.

STAM, R. Bakhtin e a crítica midiática. In: RIBEIRO, A.P.; SACRAMENTO, I. Mikhail Bakhtin: linguagem, cultura e mídia. São Paulo: Pedro \& João Editores, 2010. p.334-57.

WOLF, M. Teorias da Comunicação. Lisboa: Editorial Presença, 1987.

STACHESKI, D.R.; MASSI, G.A.A. Los índices de valor social: medios de comunicación, el lenguaje y el envejecimiento. Interface - Comunic., Saude, Educ., v.15, n.37, p.425-36, abr./jun. 2011.

Esse trabajo tuvo como objetivo analizar el discurso de los medios hacia frente al proceso de envejecimiento humano, a través de los informes publicados en el periódico Gazeta do Povo (Curitiba, Paraná, Brasil) recogidos en 2008. Las noticias fueron organizadas y analizadas a partir de los siguientes estereotipos del envejecimiento en la práctica social: el envejecimiento y la degeneración de las funciones biológicas, de la ausencia el envejecimiento y la función social de las personas mayores y el envejecimiento y los ancianos activos y responsables frente a la vejez. El estudio es de interés tanto para profesionales de la salud - tales como logopedas y psicólogos que trabajan en torno a un diseño que toma el lenguaje como constitutivo de los sujetos, como los profesionales de comunicación que trabajan con los medios de comunicación y la realización de la interferencia importante en las representaciones sociales, en el imaginario social.

Palabras clave: Envejecimiento. Medios de comunicación. Lenguaje.

Recebido em 19/05/2010. Aprovado em 10/01/2011. 